\title{
Safety and efficacy of a strategy of vitamin K antagonist reversal with prothrombin complex concentrates compared to vitamin $K$ in patients with hip fracture
}

\author{
Lucille Jay-Caillierez, MD \\ Arnaud Friggeri, MD, PhD \\ Anthony Viste, MD, PhD \\ Mathilde Lefevre, MD \\ Evelyne Decullier, PhD \\ Lorraine Bernard, MSc \\ Vincent Piriou, MD, PhD \\ Jean-Stéphane David, MD, PhD
}

Presented at the French Congress of Anesthesiology, Intensive Care and Perioperative Medicine, Sept. 16, 2015, Paris

Accepted July 3, 2020

\section{Correspondence to: \\ J.-S. David \\ Service d'Anesthésie Réanimation \\ 165, ch du Grand Revoyet \\ Centre Hospitalier Lyon Sud \\ F-69495 Pierre Bénite \\ France \\ jean-stephane.david@univ-lyon1.fr}

DOI: $10.1503 /$ cjs. 002120
Background: Increased preoperative delay in patients with hip fractures may be responsible for increased morbidity and mortality. We hypothesized that a strategy of reversal of vitamin $\mathrm{K}$ antagonist (VKA) by prothrombin complexes concentrates (PCCs), as compared to vitamin $\mathrm{K}$, is safe and reduces preoperative delay and hospital length of stay (LOS).

Methods: In this pilot study, we reviewed the records of patients admitted to a university-affiliated hospital for hip fracture between Jan. 1, 2012, and Dec. 31, 2016, who were taking VKA. Patients were stratified according to reversal strategy (vitamin $\mathrm{K}$ v. PCC). Adverse effects, time to surgery, LOS and mortality were collected from the electronic medical record and were compared between the 2 study groups and a control group not treated with VKA.

Results: A total of 141 patients were included in the study: 65 in the vitamin K group, 26 in the PCC group and 50 in the control group. The median preoperative delay in the PCC group (20 h [interquartile range (IQR)] 13-25 h]) and the control group (20 h [IQR 15-33 h]) was lower than that in the vitamin $\mathrm{K}$ group (45 h [IQR $31-52 \mathrm{~h}])(p<0.001)$. Patients in the PCC group had a shorter median hospital LOS than those in the vitamin K group (6 d [IQR 4-9 d] v. $8 \mathrm{~d}$ [IQR 6-11 d], $p<0.05)$. No difference was observed in the proportion of patients who received a red blood cell transfusion, or had thrombotic or hemorrhagic complications. No difference in mortality at 12 months was observed between the groups.

Conclusion: In patients with hip fracture, the use of PCCs as compared to vitamin K to reverse the effect of VKA significantly reduced preoperative delay and hospital LOS, and was not associated with an increase in the rates of thrombotic or hemorrhagic complications. Prospective studies involving a greater number of patients are required to confirm these promising results.

Contexte : L'allongement du délai préopératoire chez les patients atteints d'une fracture de la hanche pourrait expliquer l'augmentation de la morbidité et de la mortalité. Selon notre hypothèse, une stratégie d'inversion des antagonistes de la vitamine $K(A V K)$ au moyen de concentrés de complexes prothrombiques (CCP), plutôt que de vitamine $\mathrm{K}$, est sécuritaire et réduit le délai préopératoire et la durée du séjour hospitalier.

Méthodes : Pendant cette étude pilote, nous avons passé en revue les dossiers de patients sous AVK admis dans un centre universitaire pour fracture de la hanche entre le $1^{\text {er }}$ janvier 2012 et le 31 décembre 2016. Les patients ont été stratifiés selon la stratégie d'inversion choisie (vitamine K c. CCP). Les effets indésirables, le délai préopératoire, la durée du séjour hospitalier et la mortalité ont été recueillis à partir des dossiers médicaux électroniques et ont été comparés entre les 2 groupes de l'étude et un groupe témoin non sous AVK.

Résultats : En tout, 141 patients ont été inclus dans l'étude, 65 dans le groupe sous vitamine K, 26 dans le groupe sous CCP et 50 dans le groupe témoin. Le délai préopératoire médian pour le groupe sous CCP (20 h [éventail interquartile (ÉIQ)] 13-25 h]) et le groupe témoin (20 h [ÉIQ 15-33 h]) a été plus bref que pour le groupe sous vitamine K $(45 \mathrm{~h}$ [ÉIQ $31-52 \mathrm{~h}])(p<0,001)$. Les patients du groupe sous CCP ont eu un séjour hospitalier médian plus bref que les patients du groupe sous vitamine K (6 j [ÉIQ 4-9 j] c. 8 j [ÉIQ 6-11 j]) ( $p<0,05)$. Aucune différence n'a été observée quant à la proportion de patients ayant reçu une transfusion de culot globulaire ou ayant manifesté des complications thrombotiques ou hémorragiques. Aucune différence quant à la mortalité à 12 mois n'a été observée entre les groupes. 


\begin{abstract}
Conclusion : Chez les patients atteints d'une fracture de la hanche, l'utilisation des CCP plutôt que de la vitamine $\mathrm{K}$ pour inverser l'effet des AVK a significativement abrégé le délai préopératoire et la durée du séjour hospitalier, et n'a pas été associée à une augmentation des taux de complications thrombotiques ou hémorragiques. Des études prospectives sur un plus grand nombre de patients sont nécessaires pour confirmer ces résultats prometteurs.
\end{abstract}

$\mathrm{H}$ ip fracture is an increasing health problem worldwide that is associated with substantial morbidity and mortality, ${ }^{1,2}$ with reported 1 -year mortality rates ranging from $20 \%$ to $30 \% .3,4$ There are several studies that have explored risk factors associated with mortality, as well as various areas of management of these fractures to improve clinical outcomes..$^{5-7}$ According to a 2005 Danish study, $28 \%-57 \%$ of postoperative deaths associated with hip fracture could potentially be avoided with optimization of care, especially by reducing delay to surgery. ${ }^{8}$ Several investigators have reported that early surgery (performed within the first $2 \mathrm{~d}$ after admission) is associated with lower rates of mortality and complications, and reduced length of stay (LOS)., ${ }^{2,-11}$ Therefore, it is recommended that surgery be performed within 24-48 hours after hospital admission. ${ }^{1,12}$

However, surgery may be delayed owing to the patient's clinical condition or treatments such as anticoagulants. Among these, vitamin $\mathrm{K}$ antagonists (VKAs) are widely used for long-term oral anticoagulation therapy in patients at high risk for thromboembolic events. When these patients need urgent surgery, it is recommended that their anticoagulant's effects be antagonized with vitamin $\mathrm{K}$ or prothrombin complex concentrates (PCCs), or both, depending on the urgency of the surgery. ${ }^{13}$ For VKA reversal in patients with hip fracture, vitamin $\mathrm{K}$ is usually given and the surgery done when the international normalized ratio (INR) is less than 1.5 , which usually takes 12-14 hours after vitamin $\mathrm{K}$ administration. . $^{1415}$

By inducing potent thrombin generation, PCCs increase the risk of arterial or venous thrombosis, which is already high in patients with hip fractures. ${ }^{16,17}$ In a recent study, however, it was suggested that a VKA reversal strategy using PCCs, as compared to a combination of fresh frozen plasma and PCCs, was safe and efficient and reduced preoperative delays. ${ }^{18}$

In this pilot study, we hypothesized that rapid reversal of VKA with PCCs compared to a standard strategy of reversal with vitamin $\mathrm{K}$ would lead to a decrease in preoperative time and hospital LOS, and would not be associated with an increase in thrombotic or hemorrhagic complications.

\section{Methods}

\section{Setting, design and participants}

This retrospective study was conducted in an academic hospital located in a major city in France. Data from all patients who underwent hip fracture surgery between Jan. 1, 2012, and Dec. 31, 2016, were collected from med- ical records. We identified patients treated with VKA and defined 2 study groups according to the reversal strategy (vitamin K v. PCCs). We built the vitamin K group using the charts of patients admitted between Jan. 1, 2012, and Dec. 31, 2015, and the PCC group using the charts of those admitted between Jan. 1, 2012, and Dec. 31, 2016. An additional year of collection was required for the PCC group because of a lower number of patients in this group.

We also built a control group using the charts of patients with hip fracture admitted between Jan. 1, 2012, and Dec. 31, 2015, who were not taking an anticoagulant agent. These patients were selected at random by computerized draw from among the hospital charts.

Patients taking anticoagulant therapy other than VKA, those admitted to the hospital more than 24 hours after their injury, those with a fracture below the trochanter and those with multiple trauma were excluded from the study. We also excluded from the analysis patients who had received both vitamin $\mathrm{K}$ and PCCs.

The institutional Ethics Committee for Research in Anesthesia and Intensive Care (Comité d'Éthique pour la Recherche en Anesthésie-Réanimation) determined that the French law on medical research (Articles L.1121-1-1 and R.1121-3 of the public health code) does not apply to this retrospective observational study, and, thus, review by a research ethics board was not required.

\section{Data collection}

We retrieved the following data from the electronic medical record: patient demographic data (age, gender, weight, height, body mass index and American Society of Anesthesiologists [ASA] score); comorbidities, with calculation of the Charlson Comorbidity Index score; in-hospital data, including date and time of admission to the emergency department and of arrival in the operating room; hospital discharge date; type of fracture; characteristics of surgery performed; results of standard laboratory tests (INR, hemoglobin concentration) performed before surgery and on postoperative days 1, 3, 5 and 7; preoperative administration of vitamin K and PCCs; and perioperative administration of red blood cells. We also collected the indications for VKA treatment. In-hospital complications including thromboembolic events (including stroke), cardiac events (heart failure, myocardial infarction), pneumopathy, hemorrhagic complications and mortality during the first year after surgery were also recorded. Complications were noted and dichotomized according to whether they occurred during the first week or the first month postoperatively. 


\section{Vitamin K antagonist reversal protocol}

Patients in the vitamin $\mathrm{K}$ group received solely vitamin $\mathrm{K}$ (5-10 mg), which was ordered by the orthopedic resident and given intravenously or orally in the emergency department or the emergency surgery unit. The INR was measured 12 hours later. If the INR was 1.5 or greater, vitamin K $(5-10 \mathrm{mg})$ was given again, and the INR was checked 6-12 hours later. Surgery was performed as soon as the INR was less than 1.5. Postoperatively, prophylactic subcutaneous heparin therapy (5000 IU/12 h or low-molecularweight heparin, $4000 \mathrm{IU} / 24 \mathrm{~h}$, if the creatinine clearance was $<30 \mathrm{~mL} / \mathrm{min}$ ) was initiated 12 hours after surgery according to the orthopedic unit's protocol. Starting on the second postoperative day, subcutaneous heparin therapy was increased to achieve effective anticoagulation. On postoperative day 3 , the activated partial thromboplastin time (heparin) or anti-Xa level (low-molecular-weight heparin) was determined, and the heparin dosage was modified as necessary. Vitamin K antagonist treatment was reintroduced between postoperative day 3 and day 5 in the absence of hemorrhagic complications.

In the PCC group, when the anesthetist was notified that the patient was taking VKA, reversing VKA with PCCs rather than with vitamin $\mathrm{K}$ was left to his or her discretion. Surgery was performed as soon as possible, as for patients in the vitamin $\mathrm{K}$ group. The PCC dosage was determined according to the patient's weight and the INR (determined within $12 \mathrm{~h}$ before surgery) (Figure 1). Prothrombin complex concentrate (Octaplex, Octapharma) was given just before induction of anesthesia. The INR was not measured before surgery but was measured daily after surgery. Thromboprophylaxis as described for the vitamin $\mathrm{K}$ group was initiated 12 hours after surgery according to the orthopedic unit's protocol. In the absence of hemorrhagic complications, VKA treatment was resumed 48 or 72 hours after surgery. Prophylactic heparin therapy was discontinued when the INR was greater than 2 .

\section{Primary and secondary outcomes}

The primary outcomes were the rate of hemorrhagic or thromboembolic complications, the time elapsed from admission to the emergency department to arrival in the operating room, and the hospital LOS. Secondary outcomes were decrease in hemoglobin concentration (difference between pre- and postoperative values), red blood cell transfusion and survival at 1, 3, 6 and 12 months.

\section{Statistical analysis}

We reported descriptive data as frequency and proportion for categoric data and, according to the normality of distribution (Kolmogorov-Smirnov test), as mean and standard deviation (SD) or median and interquartile range (IQR) for continuous data. We analyzed categoric variables using the $\chi^{2}$ test or Pearson exact test, as appropriate. We analyzed continuous variable comparisons using the Student $t$ test or the Mann-Whitney $U$ test for nonparametric data. We compared the 3 groups using the Kruskal-Wallis test with post hoc Dunn test for multiple comparisons and Bonferroni correction for nonparametric data.

We performed all statistical analyses using NCSS 9.0 (NCSS Statistical Software) and MedCalc 19.1.3 (MedCalc Software). Statistical significance was defined as $p<0.05$.

\section{Results}

During the 5-year study period, 1773 patients underwent surgery for a hip fracture, 1408 in 2012-2015 and 365 in 2016 (Figure 2). A total of 141 patients were included in the study, 65 in the vitamin K group, 26 in the PCC group and 50 in the control group. There were fewer males in the PCC group than in the vitamin $\mathrm{K}$ group $(p=0.02)$ (Table 1). The median Charlson Comorbidity Index score was higher in the vitamin $\mathrm{K}$ group than in the control group, but it was not significantly different between the vitamin $\mathrm{K}$ and PCC groups (Table 1). The proportion of patients with an ASA score of 3-4 was higher in the vitamin $\mathrm{K}$ group (47 [72\%]) than in the control group (26 [52\%], $p=0.02)$, but there was no difference between the vitamin K group and the PCC group (22 [85\%]).

At admission, there was no significant difference in the median INR value between the vitamin $\mathrm{K}$ group and the PCC group, and no significant difference in hemoglobin values between the 3 study groups (Table 2). The median INR value before surgery in the vitamin $\mathrm{K}$ group was 1.4 (IQR 1.3-1.6). No significant difference was observed between groups in the median hemoglobin value 24 hours after surgery or the decrease in hemoglobin value (Table 2).

In the vitamin $\mathrm{K}$ group, 64 patients received a mean of $11 \mathrm{mg}$ (SD $5 \mathrm{mg}$ ) of vitamin $\mathrm{K}$, which was given intravenously to 47 patients (73\%). Vitamin $\mathrm{K}$ was given a median of 11 hours (IQR 8-21 h) after admission to the emergency department. In the PCC group, patients received 1702 IU (SD $645 \mathrm{IU}$ ) of PCCs just before surgery. Patients in this group had a higher median INR value on postoperative days 1 and 3 than the vitamin $\mathrm{K}$ group (Table 2). As well, more patients in the PCC group than in the vitamin $\mathrm{K}$ group had an INR value greater than 2 on postoperative day $3(8 / 17$ [47\%] v. $3 / 21$ [14\%], $p=0.04)$ and day $5(11 / 16[69 \%]$ v. $5 / 17$ [29\%]), $p=0.03)$.

\section{Thrombotic and hemorrhagic complications}

There was no between-group difference in rates of thromboembolic events or hemorrhagic complications (Table 3). No patient experienced stroke or myocardial infarction in the month after surgery, and the proportion of patients with a postoperative troponin level greater than $39 \mathrm{ng} / \mathrm{L}^{-1}$ 


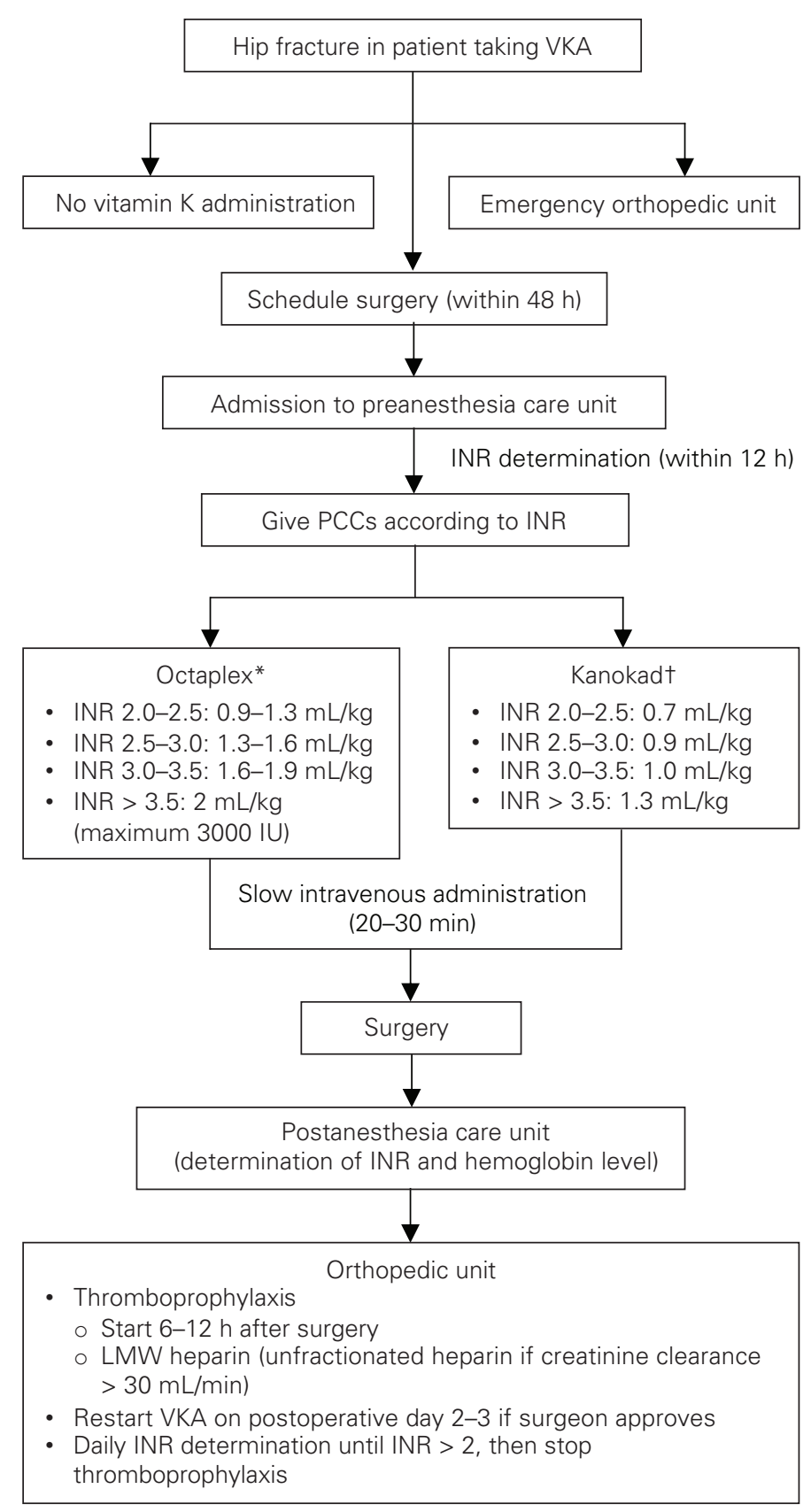

Fig. 1. Protocol for vitamin $\mathrm{K}$ antagonist (VKA) reversal with prothrombin complex concentrates (PCCs) for patients with hip fracture. *Octapharma. TVIDAL Pharma. INR = international normalized ratio; LMW = low-molecular-weight.

did not vary between the groups. Of the 141 patients, 43 $(30 \%)$ received a red blood cell transfusion (median 2.0 [IQR 1.0-2.0] units); there was no between-group difference in the proportion who received a transfusion (Table 3).

\section{Time to surgery and hospital length of stay}

The median time between admission to the emergency department and arrival in the operating room was similar in the PCC group (20 h [IQR 13-25 h]) and the control group (20 h [IQR 15-33]); the time for the vitamin $\mathrm{K}$ group was significantly longer than the times for those groups (45 h [IQR 31-52 h], $p<0.001$ ) (Figure 3). When the analysis was done according to the type of fracture, we found the same results (data not shown).

The median hospital LOS was significantly shorter in the PCC group than in the vitamin $\mathrm{K}$ group $(6 \mathrm{~d}[\mathrm{IQR}$ 4-9 d]) v. 8 d [IQR 6-11 d]) (Figure 4). 


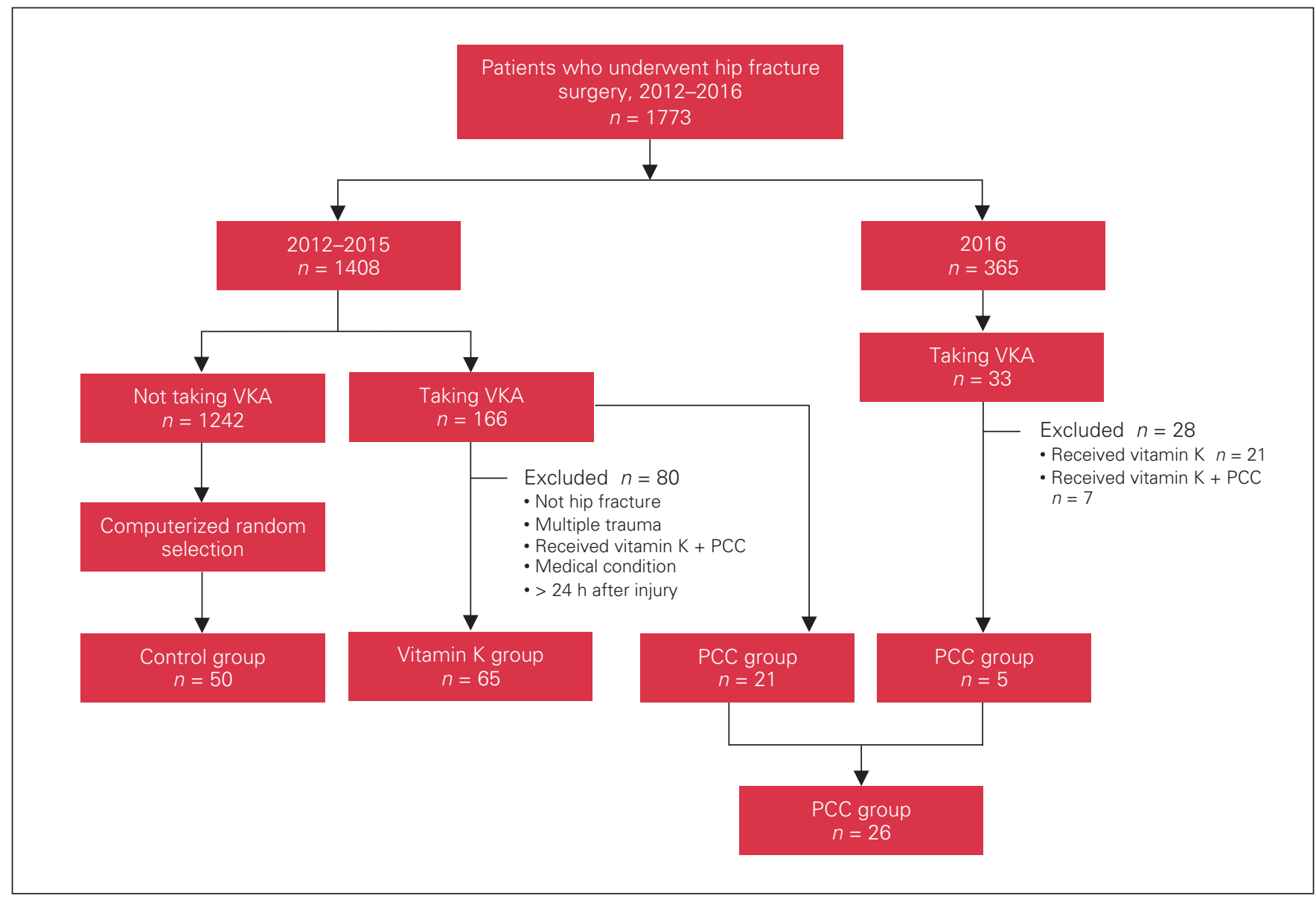

Fig. 2. Flow diagram showing selection of study groups. $P C C=$ prothrombin complex concentrate; VKA = vitamin $K$ antagonist.

\section{Survival}

No significant between-group difference was observed in survival at the various time points studied. Of the 138 patients with available data, $100(72.5 \%, 95 \%$ confidence interval $65 \%-80 \%$ ) were alive at 12 months (Table 3 ).

\section{Discussion}

In this pilot study, rapid reversal of VKA with PCCs compared to standard reversal with vitamin $\mathrm{K}$ was not associated with an increase in rates of thromboembolic or hemorrhagic complications. Time to surgery and hospital LOS were significantly shorter with the use of PCCs than with vitamin $\mathrm{K}$. A therapeutic postoperative INR value was obtained earlier in the PCC group.

To our knowledge, the use of PCCs in patients with hip fracture has previously been reported in 1 study comparing PCCs to a combination of PCCs and fresh frozen plasma for VKA reversal; however, vitamin $\mathrm{K}$ was administered in both groups. ${ }^{18}$ The authors showed that the use of PCCs was safe and efficient, and reduced the time to surgery. They cautioned against administering both fresh frozen plasma and PCCs for VKA reversal. Farley and Andreas ${ }^{19}$ described the use of PCCs without vitamin K for urgent surgery in a patient at moderate to high risk for thromboembolism. They did not report bleeding or thrombosis.

In our study, although PCCs are known to be strong inducers of thrombin generation, the use of these products was not associated with an increase in thromboembolic complication rates. Venous or arterial thromboses after PCC administration have been reported at an incidence of $1 \%-12 \%$ depending on the type of product, comorbidities and medical context. ${ }^{16,17,20,21}$ Although orthopedic surgery is associated with a high risk of venous thrombosis, ${ }^{22}$ the incidence of thrombosis was very low in our study, with no difference between groups. The low incidence of thrombosis makes it difficult to draw conclusions regarding the safety of PCC use in this context, and further study with a greater number of patients is required. The absence of an increase in thromboses in the PCC group may also have been related to the absence of vitamin $\mathrm{K}$ administration and the persistence of the VKA effect 4-6 hours after PCC administration (half-life $6 \mathrm{~h}$ ).

The persistence of the effect of VKA may also have caused an increase in postoperative bleeding. Hemorrhagic complications are observed in about $1 \%$ of patients undergoing hip fracture surgery although $40 \%$ of patients receive 
Table 1. Patient demographic and clinical characteristics

\begin{tabular}{|c|c|c|c|c|}
\hline \multirow[b]{2}{*}{ Characteristic } & \multicolumn{3}{|c|}{ Group; no. (\%) of patients* } & \multirow[b]{2}{*}{$p$ valuet } \\
\hline & $\begin{array}{c}\text { PCC } \\
n=26\end{array}$ & $\begin{array}{l}\text { Vitamin K } \\
n=65\end{array}$ & $\begin{array}{l}\text { Control } \\
n=50\end{array}$ & \\
\hline Age, median (IQR), yr & 85 (78-90) & $86(81-89)$ & 87 (82-89) & 0.7 \\
\hline Male sex & 2 (8)‡ & $24(37)$ & $14(28)$ & 0.02 \\
\hline Weight, median (IQR), kg & $61(55-74)$ & $65(55-75)$ & $60(50-70)$ & 0.06 \\
\hline $\begin{array}{l}\text { Body mass index, median } \\
\text { (IQR) }\end{array}$ & $24(21-27)$ & $23(21-26)$ & $22(20-24)$ & 0.07 \\
\hline \multicolumn{2}{|l|}{ ASA score } & & & 0.04 \\
\hline 2 & $4(15)$ & $18(28)$ & $24(48)$ & - \\
\hline 3 & $20(77)$ & $42(65)$ & $24(48)$ & - \\
\hline 4 & $2(8)$ & $5(8)$ & $2(4)$ & - \\
\hline $\begin{array}{l}\text { Charlson Comorbidity Index } \\
\text { score, median (IQR) }\end{array}$ & $5(4-7)$ & $6(5-7)$ & $5(4-7) \ddagger$ & 0.02 \\
\hline \multicolumn{2}{|l|}{ Surgical procedure } & & & 0.99 \\
\hline Hip replacement & $11(42)$ & $28(43)$ & $22(44)$ & - \\
\hline Other & $15(58)$ & $37(57)$ & $28(56)$ & - \\
\hline \multicolumn{2}{|l|}{ Type of fracture } & & & 0.99 \\
\hline Neck & $13(50)$ & $33(51)$ & $25(50)$ & - \\
\hline Trochanter & $13(50)$ & $32(49)$ & $25(50)$ & - \\
\hline \multicolumn{2}{|l|}{ Indication for VKA } & & & 0.3 \\
\hline Atrial fibrillation & $21(81)$ & $44(68)$ & - & - \\
\hline $\begin{array}{l}\text { Deep vein thrombosis/ } \\
\text { pulmonary embolism }\end{array}$ & $2(8)$ & $13(20)$ & - & - \\
\hline Other & $3(12)$ & $8(12)$ & - & - \\
\hline \multicolumn{5}{|c|}{$\begin{array}{l}\text { ASA = American Society of Anesthesiologists; IQR }=\text { interquartile range; } \mathrm{PCC}=\text { prothrombin complex concentrate; VKA }=\text { vitamin } \mathrm{K} \\
\text { antagonist. } \\
\text { *Except where noted otherwise. } \\
+ \text { For between-group differences determined with the } \chi^{2} \text { test with post hoc test, or Kruskal-Wallis test with post hoc analysis with the Dunn } \\
\text { test and Bonferroni correction. } \\
\neq p<0.05 \text { for difference with vitamin } \mathrm{K} \text { group. }\end{array}$} \\
\hline
\end{tabular}

\begin{tabular}{|c|c|c|c|c|}
\hline \multirow[b]{2}{*}{ Variable } & \multicolumn{3}{|c|}{ Group; median (IOR)* } & \multirow[b]{2}{*}{$p$ value* } \\
\hline & PCC & Vitamin K & Control & \\
\hline \multicolumn{5}{|l|}{ Hemoglobin concentration, g/dL } \\
\hline Admissiont & $12.1(11.1-13.7)$ & $12.7(11.4-13.8)$ & $12.5(11.4-13.4)$ & 0.6 \\
\hline Postoperative day 1 & $10.0(8.8-12.2)$ & $10.5(9.4-11.8)$ & $10.6(9.1-11.6)$ & 0.8 \\
\hline $\begin{array}{l}\delta \text { Hemoglobin concentration, mean } \\
\pm \text { SD } \neq\end{array}$ & $-1.6 \pm 1.0$ & $-2.1 \pm 1.4$ & $-1.7 \pm 1.6$ & 0.2 \\
\hline \multicolumn{5}{|l|}{ International normalized ratio } \\
\hline Admission§ & $2.5(2.3-3.2)$ & $2.5(2.1-2.9)$ & - & 0.3 \\
\hline Postoperative day 1 & $1.8(1.5-2.1)$ & $1.2(1.1-1.4)$ & - & $<0.05$ \\
\hline Postoperative day 3 & $1.7(1.4-2.4)$ & $1.2(1.1-1.5)$ & - & $<0.05$ \\
\hline Postoperative day 5 & $2.4(1.3-3.2)$ & $1.9(1.5-2.3)$ & - & 0.2 \\
\hline $\begin{array}{l}\text { Red blood cell administration, no. } \\
\text { (\%) of patients }\end{array}$ & $4(15)$ & $21(32)$ & $18(36)$ & 0.2 \\
\hline $\begin{array}{l}\text { Units of red blood cells } \\
\text { administered }\end{array}$ & $1.5(1.0-2.8)$ & $2.0(1.0-2.0)$ & $2.0(1.0-2.0)$ & 0.9 \\
\hline \multicolumn{5}{|c|}{$\begin{array}{l}\text { IQR = interquartile range; } P C C=\text { prothrombin complex concentrate; } S D=\text { standard deviation. } \\
\text { *For between-group differences determined with the } \chi^{2} \text { test with post hoc test or, for quantitative parameters, the Mann-Whitney U test or } \\
\text { Kruskal-Wallis test with post hoc analysis with the Dunn test and Bonferroni correction. } \\
\text { †Missing for } 1 \text { patient in the PCC group and } 1 \text { patient in the vitamin K group. } \\
\text { fDecrease between admission and postoperative day } 1 . \\
\text { §Missing for } 1 \text { patient in the PCC group. }\end{array}$} \\
\hline
\end{tabular}

a red blood cell transfusion, ${ }^{22-24}$ similar to the proportion in the present study: roughly one-third of our patients required a red blood cell transfusion during surgery or in the days thereafter, without any significant difference between the 3 study groups. In addition, some of the factors included in PCCs, such as factor II and factor X, 


\begin{tabular}{|c|c|c|c|c|}
\hline \multirow[b]{2}{*}{ Variable } & \multicolumn{3}{|c|}{ Group; no. (\%) of patients } & \multirow[b]{2}{*}{$p$ value* } \\
\hline & PCC & Vitamin K & Control & \\
\hline \multicolumn{5}{|l|}{ Complications } \\
\hline \multicolumn{5}{|l|}{ Venous thrombosis } \\
\hline First month & $1(4)$ & $0(0)$ & $0(0)$ & 0.1 \\
\hline \multicolumn{5}{|l|}{ Arterial thrombosis } \\
\hline First $7 \mathrm{~d}$ & $0(0)$ & $0(0)$ & $1(2)$ & 0.4 \\
\hline First month & $0(0)$ & $0(0)$ & $1(2)$ & 0.4 \\
\hline \multicolumn{5}{|l|}{ Hemorrhage at surgical site } \\
\hline First $7 \mathrm{~d}$ & $0(0)$ & 2 (3) & $0(0)$ & 0.3 \\
\hline First month & $1(4)$ & $3(5)$ & $0(0)$ & 0.3 \\
\hline \multicolumn{5}{|c|}{ Hemorrhage outside surgical site } \\
\hline First month & $1(4)$ & $2(3)$ & $0(0)$ & 0.4 \\
\hline \multicolumn{5}{|l|}{ Cardiac eventst } \\
\hline First $7 d$ & $2(8)$ & 2 (3) & $5(10)$ & 0.3 \\
\hline First mo & $3(12)$ & $3(5)$ & $6(12)$ & 0.3 \\
\hline \multicolumn{5}{|l|}{ Troponin level > $39 \mathrm{ng} / \mathrm{L}^{-1}$} \\
\hline Postoperative day 1 & $5 / 23(22)$ & $9 / 40(22)$ & $9 / 58(16)$ & 0.6 \\
\hline Postoperative day 3 & $4 / 18(22)$ & $13 / 41(32)$ & $18 / 36(50)$ & 0.1 \\
\hline Postoperative day 5 & $3 / 12(25)$ & $4 / 32(12)$ & $10 / 29(34)$ & 0.1 \\
\hline Pneumopathy at 1 mo & $2(8)$ & 2 (3) & $2(4)$ & 0.6 \\
\hline \multicolumn{5}{|l|}{ Survival¥ } \\
\hline $1 \mathrm{mo}$ & $23(88)$ & $60(92)$ & $45(90)$ & 0.8 \\
\hline $3 \mathrm{mo}$ & $23(88)$ & $56(86)$ & $39(81)$ & 0.7 \\
\hline $6 \mathrm{mo}$ & $22(88)$ & $52(80)$ & $37(77)$ & 0.5 \\
\hline $12 \mathrm{mo}$ & $18(72)$ & $46(71)$ & $36(75)$ & 0.9 \\
\hline \multicolumn{5}{|c|}{$\begin{array}{l}\text { PCC = prothrombin complex concentrate. } \\
\text { *For differences between study groups. } \\
\text { tIncludes cardiac failure, arrhythmia and myocardial ischemia. } \\
\text { ‡Survival was unknown for } 2 \text { patients in the control group at } 3,6 \text { and } 12 \text { months, and for } 1 \text { patient in the PCC group at } 6 \\
\text { and } 12 \text { months because of loss to follow-up. }\end{array}$} \\
\hline
\end{tabular}

have half-lives longer than about 6 hours $(60-72 \mathrm{~h}$ and $40-45 \mathrm{~h}$, respectively), ${ }^{25}$ which confers a longer duration of efficient hemostasis and makes the administration of vita$\min \mathrm{K}$ less useful.

In the present study, time to surgery was shorter with a reversal strategy based on PCCs rather than one based on vitamin $\mathrm{K}$, which made it possible to perform surgery in the first 24 hours after admission to the emergency department. Several investigators have suggested that a reduction in preoperative delay may improve outcomes of patients with hip fracture..$^{2,8,26-28} \mathrm{In}$ a retrospective study in a cohort of more than 42000 patients with hip fracture, Pincus and colleagues $^{2}$ found greater mortality and more frequent complications when the delay to surgery was more than 24 hours. In a 2012 meta-analysis of 35 studies including nearly 200000 patients, Moja and colleagues ${ }^{27}$ found similar results when the delay exceeded 24-48 hours.

Early surgical management is also reported to reduce morbidity, with less frequent cardiovascular events, postoperative confusion and infectious complications. , $^{41,29}$ Although a mean surgical management time of less than 24 hours for $50 \%-60 \%$ of patients undergoing hip fracture surgery has been reported, ${ }^{27,28}$ the time to surgery can be longer, especially for patients taking anticoagulants. ${ }^{15}$ In the current study, the median time to surgery for patients in the vitamin $\mathrm{K}$ group was more than twice that for those in the PCC group, corresponding to the time required to obtain an INR value less than 1.5. This delay is similar to that observed by Pincus and colleagues ${ }^{2}$ (mean time to surgery $39 \mathrm{~h}$ [SD $29 \mathrm{~h}]$ ), who reported that $66 \%$ of patients had surgery more than 24 hours after admission.

Reduction of surgical management time must therefore be considered as a therapeutic goal to improve the prognosis in patients with hip fracture. This goal is in line with the current trend to provide fast-track surgery for patients with hip fracture, as for those needing colorectal surgery. ${ }^{1,5,12}$

The use of PCCs was also associated with a shorter LOS compared to the vitamin $\mathrm{K}$ group. There is an increased demand for geriatric care related to the aging of the population in western Europe and North America, and geriatric care units are frequently full. For patients taking VKA, a reversal strategy based on PCCs may be a solution to help increase the turnover of surgical beds. However, the use of PCCs is more expensive than that of vitamin $\mathrm{K}$, with a cost of about $€ 40$ (about Can\$59) per $100 \mathrm{IU}$. In the calculation of costs, it should be noted that VKA therapy was resumed earlier in the PCC group, with a lower use of heparinoids. The absence of vitamin $\mathrm{K}$ 


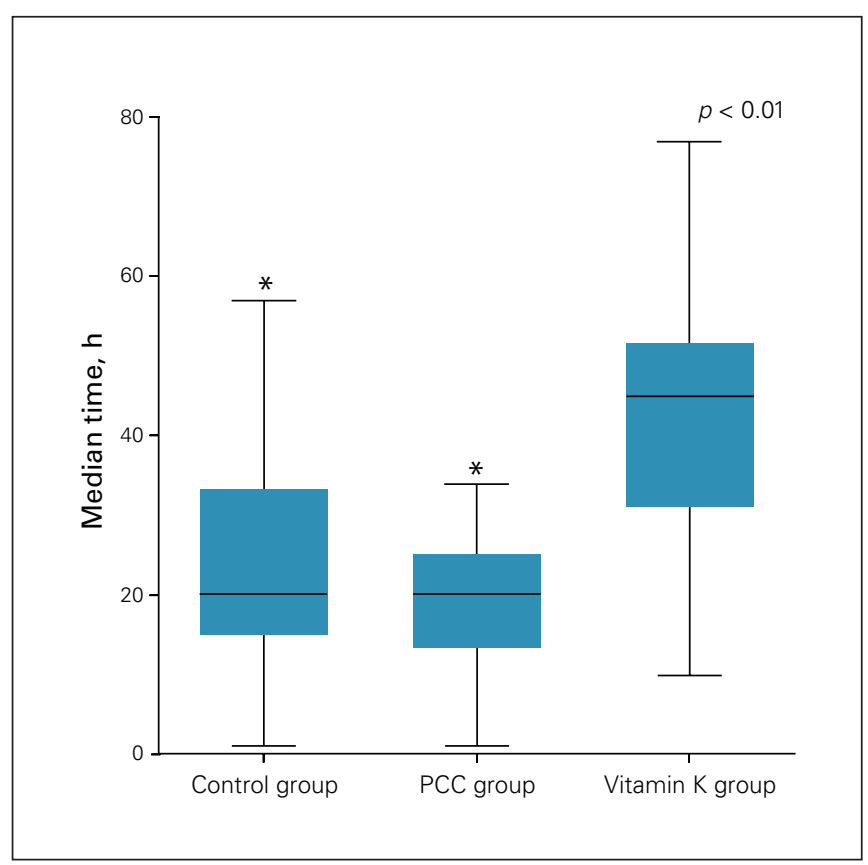

Fig. 3. Median time (and 25th-75th percentile) between emergency department admission and arrival in operating room. Error bars represent adjacent values. $p$ value refers to between-group difference (Kruskal-Wallis test) with post hoc analysis with Dunn test and Bonferroni correction. ${ }^{*} p<0.05$. PCC $=$ prothrombin complex concentrate.

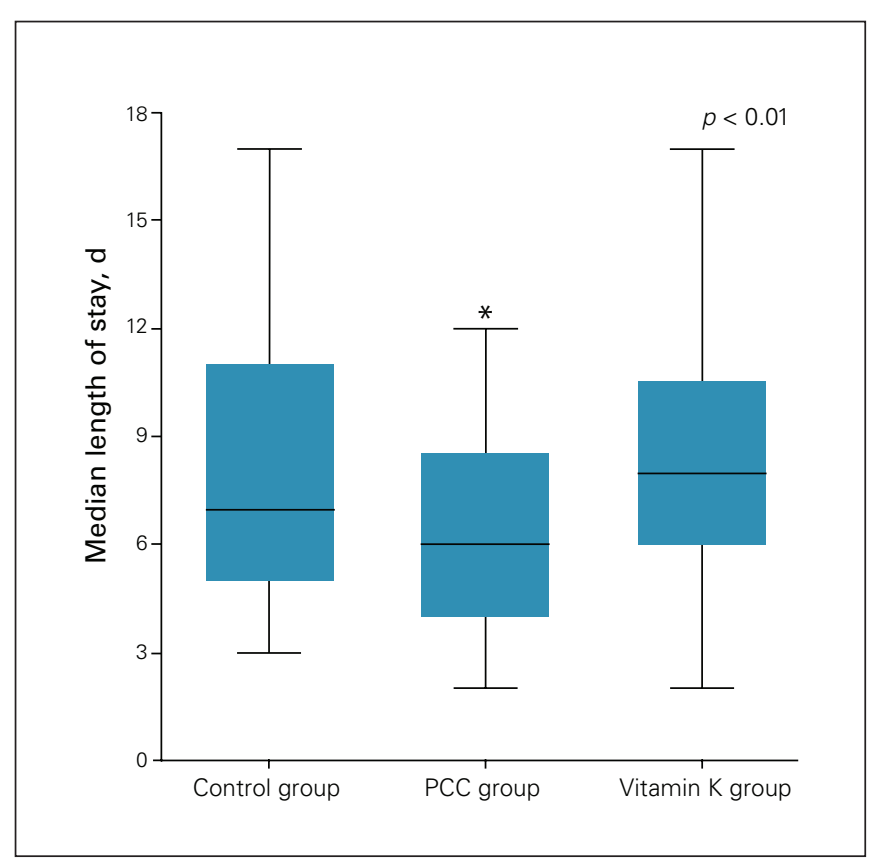

Fig. 4. Median hospital length of stay (and 25th-75th percentile). Error bars represent adjacent values. $p$ value refers to betweengroup difference (Kruskal-Wallis test) with post hoc analysis with Dunn test and Bonferroni correction. ${ }^{*} p<0.05$. PCC $=$ prothrombin complex concentrate.

use allowed more rapid rebalancing of the INR in patients in the PCC group, which avoided complications associated with prolonged bridging with heparin therapy, such as hemorrhage. ${ }^{30}$
We did not observe a significant difference in survival between the PCC and vitamin K groups, despite a shorter time to surgery in the former. This was probably due to the small sample size, as well as the fact that improvement in outcomes is multifactorial, including other factors such as the provision of comprehensive geriatric care. ${ }^{31}$

\section{Limitations}

This was a retrospective study, with a significant risk of "protocol effect," loss of information and misclassification, particularly concerning the occurrence of complications in the months after surgery. However, the follow-up period for death was 12 months, and no difference was observed between the 3 groups. To adjust for the risk of protocol effect, we used a control group and showed, for example, the absence of difference for the delay before surgery between the PCC and the control group.

We observed differences in patient characteristics between the 3 groups that were inherent to the retrospective design of the study. Differences were observed for demographic data such as the sex ratio. However, the PCC and vitamin $\mathrm{K}$ groups did not differ significantly in medical history, ASA score or Charlson Comorbidity Index score. In addition, the size of the study groups was different, with fewer patients in the PCC group. This may have limited the ability to detect postoperative complications or an effect on mortality, which suggests that a similar study will have to be performed with a greater number of patients and a prospective randomized design.

It could be argued that, if vitamin $\mathrm{K}$ had been given earlier, the time to surgery may not have been different between the PCC and vitamin K groups. We therefore compared the delay between emergency department admission and surgery in the PCC group to the delay between vitamin $\mathrm{K}$ administration and surgery in the vitamin $\mathrm{K}$ group and observed that the delay to surgery was still shorter in the PCC group $(p=0.03)$.

\section{Conclusion}

The results of this pilot study suggest that reversal of VKA by PCCs, as compared to a reversal strategy with vita$\min \mathrm{K}$, for patients with hip fracture is feasible and is not associated with an increase in thromboembolic complication rates. It led to a reduction in preoperative delay and a shorter hospital LOS. Prospective studies involving a greater number of patients are required to confirm these promising results.

Affiliations: From the Service d'Anesthésie Réanimation, Hospices Civils de Lyon, Groupement Hospitalier Sud, Pierre Bénite, France (JayCaillierez, Friggeri, Lefevre, Piriou, David); the Service Recherche et Epidémiologie Cliniques, Pôle Santé Publique, Hospices Civils de Lyon, Lyon, France (Decullier, Lorraine); the EA Santé Individu Société, Université Claude Bernard Lyon 1, Lyon, France (Decullier, Bernard); the Service de Chirurgie Orthopédique, Hospices Civils de Lyon, 
Groupement Hospitalier Sud, Pierre Bénite, France (Viste); IFSTTAR, UMR-T9406, Laboratoire de Biomécanique et Mécanique des Chocs, Bron, France (Viste); and the Faculté de Médecine, Université Claude Bernard Lyon 1, Lyon, France (Friggeri, Viste, Piriou, David).

Competing interests: Jean-Stéphane David has delivered lectures and consulted for LFB Laboratory. No other competing interests were declared.

Contributors: L. Jay-Caillierez, M. Lefevre, V. Piriou and J.-S. David designed the study. L. Jay-Caillierez acquired the data, which A. Friggeri, A. Viste, E. Decullier and L. Bernard analyzed. J.-S. David wrote the manuscript, which all authors critically revised. All authors gave final approval of the article to be published.

Content licence: This is an Open Access article distributed in accordance with the terms of the Creative Commons Attribution (CC BYNC-ND 4.0) licence, which permits use, distribution and reproduction in any medium, provided that the original publication is properly cited, the use is noncommercial (i.e., research or educational use), and no modifications or adaptations are made. See: https://creativecommons. org/licenses/by-nc-nd/4.0/.

\section{References}

1. Bhandari M, Swiontkowski M. Management of acute hip fracture. $N$ Engl f Med 2017;377:2053-62.

2. Pincus D, Ravi B, Wasserstein D, et al. Association between wait time and 30-day mortality in adults undergoing hip fracture surgery. 7AMA 2017;318:1994-2003.

3. Daugaard CL, Jørgensen HL, Riis T, et al. Is mortality after hip fracture associated with surgical delay or admission during weekends and public holidays? Acta Orthop 2012;83:609-13.

4. Mariconda M, Costa GG, Cerbasi S, et al. The determinants of mortality and morbidity during the year following fracture of the hip. Bone foint 7 2015;97-B:383-90.

5. Boddaert J, Raux M, Khiami F, et al. Perioperative management of elderly patients with hip fracture. Anesthesiology 2014;121:1336-41.

6. Mazzocato P, Unbeck M, Elg M, et al. Unpacking the key components of a programme to improve the timeliness of hip-fracture care: a mixedmethods case study. Scand 7 Trauma Resusc Emerg Med 2015;23:93.

7. HIP ATTACK Investigators. Accelerated surgery versus standard care in hip fracture (HIP ATTACK): an international, randomised, controlled trial. Lancet 2020;395:698-708.

8. Foss NB, Kehlet H. Mortality analysis in hip fracture patients: implications for design of future outcome trials. Br 7 Anaesth 2005;94:24-9.

9. Shiga T. Wajima $\mathrm{Zi}$, Ohe Y. Is operative delay associated with increased mortality of hip fracture patients? Systematic review, metaanalysis, and meta-regression. Can F Anaesth 2008;55:146.

10. Ryan DJ, Yoshihara H, Yoneoka D, et al. Delay in hip fracture surgery: an analysis of patient-specific and hospital-specific risk factors. f Orthop Trauma 2015;29:343.

11. Lefaivre KA, Macadam SA, Davidson DJ, et al. Length of stay, mortality, morbidity and delay to surgery in hip fractures. 7 Bone foint Surg Br 2009;91:922-7.

12. Aubrun F, Baillard C, Beuscart JB, et al. Recommandation sur l'anesthésie du sujet âgé: l'exemple de fracture de l'extrémité supérieure du fémur. Anesthesie Reanimation 2019;5:122-38.

13. Tomaselli GF, Mahaffey KW, Cuker A, et al. 2017 ACC Expert Consensus Decision Pathway on Management of Bleeding in
Patients on Oral Anticoagulants: a report of the American College of Cardiology Task Force on Expert Consensus Decision Pathways. $\mathcal{F}$ Am Coll Cardiol 2017;70:3042-67.

14. Leonidou A, Rallan R, Cox N, et al. Comparison of different warfarin reversal protocols on surgical delay and complication rate in hip fracture patients. F Orthop Surg (Hong Kong) 2013;21:142-5.

15. Buecking B, Eschbach D, Bliemel C, et al. Effectiveness of vitamin K in anticoagulation reversal for hip fracture surgery - a prospective observational study. Thromb Res 2014;133:42-7.

16. Sørensen B, Spahn DR, Innerhofer P, et al. Clinical review: prothrombin complex concentrates - evaluation of safety and thrombogenicity. Crit Care 2011;15:201.

17. Ghadimi K, Levy JH, Welsby IJ. Prothrombin complex concentrates for bleeding in the perioperative setting. Anesth Analg 2016;122: 1287-300.

18. $\mathrm{Ng}$ R, Shabani-Rad MT. Results of Octaplex for reversal of warfarin anticoagulation in patients with hip fracture. Can F Surg 2019;62:14-9.

19. Farley TM, Andreas EM. Reversal of anticoagulation with fourfactor prothrombin complex concentrate without concurrent vitamin $\mathrm{K}$ (phytonadione) for urgent surgery in a patient at moderate-to-high risk for thromboembolism. BMF Case Rep 2016;bcr2016217092.

20. Dentali F, Marchesi C, Pierfranceschi MG, et al. Safety of prothrombin complex concentrates for rapid anticoagulation reversal of vitamin K antagonists. Thromb Haemost 2011;106:429-38.

21. Sridharan M, Wysokinski WE, Pruthi R, et al. Periprocedural warfarin reversal with prothrombin complex concentrate. Thromb Res 2016;139:160-5.

22. Rosencher N, Vielpeau C, Emmerich J, et al. Venous thromboembolism and mortality after hip fracture surgery: the ESCORTE study. 7 Thromb Haemost 2005;3:2006-14.

23. Morris R, Rethnam U, Russ B, et al. Assessing the impact of fracture pattern on transfusion requirements in hip fractures. Eur 7 Trauma Emerg Surg 2017;43:337-42.

24. Desai SJ, Wood KS, Marsh J, et al. Factors affecting transfusion requirement after hip fracture: Can we reduce the need for blood? Can 7 Surg 2014;57:342-8.

25. Ghadimi K, Levy JH, Welsby IJ. Prothrombin complex concentrates for bleeding in the perioperative setting. Anesth Analg 2016;122: 1287-300.

26. Bohm E, Loucks L, Wittmeier K, et al. Reduced time to surgery improves mortality and length of stay following hip fracture: results from an intervention study in a Canadian health authority. Can $\mathcal{F}$ Surg 2015;58:257-63.

27. Moja L, Piatti A, Pecoraro V, et al. Timing matters in hip fracture surgery: patients operated within 48 hours have better outcomes. A meta-analysis and meta-regression of over 190,000 patients. PLoS One 2012;7:e46175.

28. Bottle A, Aylin P. Mortality associated with delay in operation after hip fracture: observational study. BM7 2006;332:947-51.

29. Orosz GM, Magaziner J, Hannan EL, et al. The timing of surgery for hip fracture and its effects on outcomes. FAMA 2004;291:1738.

30. Douketis JD, Spyropoulos AC, Kaatz S, et al. Perioperative bridging anticoagulation in patients with atrial fibrillation. N Engl 7 Med 2015; 373:823-33.

31. Prestmo A, Hagen G, Sletvold O, et al. Comprehensive geriatric care for patients with hip fractures: a prospective, randomised, controlled trial. Lancet 2015;385:1623-33. 